\title{
Predictors of mortality in a cohort of tuberculosis/HIV co-infected patients in Southwest Ethiopia
}

\author{
Hailay Gesesew ${ }^{1,2}$, Birtukan Tsehayneh ${ }^{1,3}$, Desalegn Massa ${ }^{1}$, Amanuel Gebremedhin ${ }^{4}$, Hafte Kahsay ${ }^{5}$
} and Lillian Mwanri $2^{*}$

\begin{abstract}
Background: Tuberculosis/HIV co-infection is a bidirectional and synergistic combination of two very important pathogens in public health. To date, there have been limited clinical data regarding mortality rates among tuberculosis/HIV co-infected patients and the impact of antiretroviral therapy on clinical outcomes in Ethiopia. This study assessed the incidence and predictors of tuberculosis/HIV co-infection mortality in Southwest Ethiopia.

Methods: A retrospective cohort study collated tuberculosis/HIV data from Jimma University Teaching Hospital for the period of September 2010 and August 2012. The data analysis used proportional hazards cox regression model at $P$ value of $\leq 0.05$ in the final model.

Results: Fifty-five (20.2\%) patients died during the study period and 272 study participants contributed 3 082.7 person month observations. Factors including: being aged between $35-44$ years (AHR $=2.9 ; 95 \% \mathrm{Cl}$ : 1.08-7.6), being a female sex worker (AHR $=9.1 ; 95 \% \mathrm{Cl}$ : 2.7-30.7), being bed ridden as functional status $(A H R=3.2 ; 95 \% \mathrm{Cl}: 1.2-8.7)$, and being at World Health Organization HIV disease stages 2 (AHR $=0.2$; $95 \% \mathrm{Cl}: 0.06-0.5), 3(\mathrm{AHR}=0.3 ; 95 \% \mathrm{Cl}: 0.1-0.8)$ and $4(\mathrm{AHR}=0.2 ; 95 \% \mathrm{Cl}: 0.04-0.55)$ were significant predictors of mortality for tuberculosis/HIV co-infected patients.

Conclusions: Contrary to our expectations, the World Health Organization (WHO) HIV disease stage 1 was found to be a significant predictor of mortality. Higher mortality rates were observed in WHO disease stage 1 patients compared to patients in stages 2,3 and 4. The current study also confirmed and reaffirmed known significant predictors of the mortality for tuberculosis/HIV co-infected patients including being 35-44 years, being a female sex worker and being bed ridden functional status. The occurrence of high death rate among tuberculosis/HIV co-infected cases needs actions to reduce this poor outcome.
\end{abstract}

Keywords: Tuberculosis, HIV, Co-infection, Mortality, Survival, Retrospective cohort, Ethiopia

\section{Multilingual abstract}

Please see Additional file 1 for translation into the five official working languages of the United Nations.

\section{Background}

Tuberculosis/HIV (TB/HIV) co-infection causes a serious bidirectional and synergistic combination of

\footnotetext{
*Correspondence: lillian.mwanri@flinders.edu.au

${ }^{2}$ Discipline of Public Health, Faculty of Medicine, Nursing and Health

Sciences, Flinders University, Adelaide, Australia

Full list of author information is available at the end of the article
}

illness in which HIV promotes the progression of latent tuberculosis infection to disease, and tuberculosis (TB) accelerates the progression of HIV disease to poor prognosis including death [1]. In many circumstances, HIV has been described as the main reason for failure to meet TB control targets in high HIV settings, and TB is a major cause of death among people living with HIV in similar settings [2]. It is also recognised that individuals with TB/HIV co-infection are highly likely to develop active TB disease than individuals without HIV [3] According to the 2010 World Health Organization HIV 
disease stages (WHO) report on TB profiles for different countries, Ethiopia was classified as a high burden TB, a high burden HIV and a high burden Multi-drug resistance TB (MDR-TB) nation [3]. The prevalence of TB was estimated to be 394 (173-623) per 100000 populations including those co-infected with HIV, and there were 152030 new cases of which 3190 were below 15 years of age [2].

Worldwide, TB remains one among the leading causes of death from an infectious agent. For example, in 2014, an estimated 9.6 million people developed TB, of which 1.2 million (12\%) were co-infected with HIV [4]. In 2015, $33 \%$ of HIV deaths were due to TB showing that it is still a leading killer of HIV-positive people [5]. Different studies have indicated that TB is often the first manifestation of HIV infection, and it is the leading cause of death among HIV-infected patients in Africa [6, 7]. Globally, a third (33\%) of population living with HIV are infected with TB, and more than two third (70 \%) of TB patients have been reported to live with HIV in Sub-Saharan Africa [3, 7]. In 2004, a study conducted in Ethiopia reported a TB/HIV coinfection prevalence of $18 \%$ ranging from $8.3 \%$ (in Silte zone) to $35.3 \%$ (in South Omo zone) [8]. In 2015, according to the study conducted in south Ethiopia [9], $18.2 \%$ of the HIV infected patients were found to have tuberculosis.

A wide range of factors that influence TB/HIV coinfection mortality have been reported. These include: age, gender, marital status, level of education, religion, occupation, residence, weight, AIDS staging, TB clinical presentation and calendar year $[10,11]$. Previous studies have focused mainly on the survival rates of general HIV patients, giving less attention to $\mathrm{TB} / \mathrm{HIV}$ co-infected patients [12-15]. A few studies in Ethiopia have analysed factors associated with mortality in HIV-infected TB patients [16, 17] and some studies [18, 19] took into account drug susceptibility patterns of Mycobacterium tuberculosis outside Ethiopia. However, these studies assessed the mortality rates of HIV positive and negative patients on anti-TB treatment. To date, there have been limited clinical data regarding mortality rates among TB/HIV co-infected patients and the impact of antiretroviral therapy (ART) on clinical outcomes in Ethiopia. The aim of the current study was to investigate the mortality rate of TB/HIV co-infected patients who developed TB after commencing ART in order to gain a better insight of the associated factors.

\section{Methods}

The study was conducted in Jimma University Teaching Hospital (JUTH), $357 \mathrm{~km}$ southwest of Addis Ababa, the Capital City of Ethiopia. Jimma town is situated in Oromia region, a region that accounts for the highest number of HIV infected people in Ethiopia [20]. Jimma is also located near Gambella, a region that contributes the highest prevalence rate of HIV in Ethiopia [20]. A refugee camp located near the study setting zone brings in a large number of refugees from different African countries (particularly South Sudan), and the high emigration and immigration from and to Jimma places this town at a heightened risk of HIV and TB infection and transmission. Jimma teaching hospital is the largest health facility in Jimma town, its catchment area comprising a population of 2486155 inhabitants of which $89.69 \%$ are rural dwellers [21]. The hospital caters for both Jimma and Gambella zones providing a substantial amount and important data which were favourable for this study.

A retrospective cohort study was conducted using JUTH records from September 1, 2010 to August 31 2012. The target population was all patients aged 15 years and above, who were HIV infected, on ART and developed TB when receiving the care from JUTH.

Death due to any cause was the event. Age, sex, religion, educational level, marital status, occupation, residence, number of people living in the household, accessibility to safe water, accessibility of electricity, number of bedrooms in the household, functional status, baseline CD4 cells count, drug regimen, WHO clinical disease stage, disclosure, risky sexual behaviour, tobacco smoking and alcohol drinking were the independent variables. WHO clinical disease staging was defined based on the current ART guideline for Ethiopia [22]. A risky sexual behaviour was dichotomized as 'no' (has regular sexual partner in the last three months) and 'yes' (has one or more casual sexual partners in the last three months). Condom use was also dichotomized as yes if 'use rarely, sometimes, mostly or always during sexual intercourse', and no if 'never use during sexual intercourse'. Patients were considered as alcohol consumers if 'they drink rarely, sometimes, mostly or always' in their lifetime. Similarly, they were considered as cigarette smokers if 'they smoke rarely, sometimes, mostly or always' in lifetime.

Data extraction was performed between August and October 2013. A data extraction checklist (Annex I) was used to collect information from the patient cards, registration and log books. Data were entered in to Epi-data and then exported to SPSS version 22.0 for mackintosh for analysis. Incomplete records were excluded from analysis. The main end point in this study was death due to any cause among the TB/HIV co-infected patients. Individuals defaulted, lost to follow up, transferred out and survivors at the end of the study period were considered as censored. Finally, the out-come of each subject was dichotomized in to censored or event. The data were cleaned and edited before analysis. Data editing and exploration was undertaken to exclude odd codes or items that were illogical. 
The analysis of both descriptive and inferential statistics was conducted. The cohort descriptive statistics included mean, median, standard deviations, and range values for continuous data; percentage, frequency tables, and graphs for categorical data. For the comparison of time to recovery among the different groups of patients, Kaplan Meir curve was used. Bivariate and multiple cox regression model with stepwise variable selection procedural was used to identify independent predictors of mortality. The assumption for proportional hazard was assessed graphically. Variables with $P$-value of $<0.25$ in the bivariate cox regression analysis were considered as candidate variables for multiple cox regression analysis. $P$-value of $\leq 5 \%$ was considered significant in the final model.

\section{Results}

Baseline socio-demographic and economic characteristics of the study participants

Table 1 describes baseline socio-demographic and economic characteristics of the study participants. Two hundred eighty nine (289) TB/HIV co-infected patients were registered during September 1, 2010 and August 31, 2012. Complete records of 272 TB/HIV co-infected patients followed up for a mean of 340 days were included in the study. The mean age of the study participants was $32( \pm 8.53)$ years with the majority of patients aged between $25-34$ years. More than half (58.3\%) of the study participants were females. Muslims by religion and daily labourers by occupation respectively, represented $58.1 \%$ and $31.6 \%$ of participants. Almost half $(51.5 \%)$ and $60.7 \%$ of participants respectively were formally educated and married. In terms of residence, almost $70 \%$ of them were urban dwellers. A significant proportion $(76.1 \%)$ of participants had water and electricity in their residence and less than five people resided in the household. A significant number of participants lived in a single bedroomed (44.5\%) or two bedroomed (40.5\%) households.

\section{Clinical and behavioural characteristics of the study participants}

Table 2 presents clinical and behavioural characteristics of the study participants. In the cohort, 176 (64.7 \%) participants had disclosed about their HIV status to their closest person such as their sexual partner or the next of kin. The majority of the patients were on first line ART regimen, working functional status and WHO stage 3. About $60 \%$ of the study participants had low CD4 count ( $<200$ cells/copies) and the median (range) CD4 count was 172.5 (425) cells/copies. When compared to other types of TB (extra pulmonary or mixed), pulmonary TB accounted for the majority (78.3\%) of cases. More than $85 \%$ of patients had accessed the service care as new TB cases. Nearly $70 \%$ of participants' sexual partners
Table 1 Baseline socio-demographic characteristics of Tb/HIV co-infected patients at JUTH, Southwest Ethiopia, 2013

\begin{tabular}{|c|c|c|c|}
\hline Variable $(n=272)$ & Value & Number & Percent \\
\hline \multirow[t]{4}{*}{ Age (in years) } & $15-24$ & 38 & 13.9 \\
\hline & $25-34$ & 140 & 51.5 \\
\hline & $35-44$ & 69 & 25.4 \\
\hline & $>=45$ & 25 & 9.2 \\
\hline \multirow[t]{2}{*}{ Sex } & Male & 114 & 41.9 \\
\hline & Female & 158 & 58.1 \\
\hline \multirow[t]{5}{*}{ Occupation } & Government employed & 48 & 17.7 \\
\hline & $\mathrm{NGO}^{*}$ & 46 & 16.9 \\
\hline & Farmer & 80 & 29.4 \\
\hline & Daily labor & 86 & 31.6 \\
\hline & Commercial Sex Worker & 12 & 4.4 \\
\hline \multirow[t]{3}{*}{ Educational status } & Illiterate & 81 & 29.8 \\
\hline & Read and write & 51 & 18.8 \\
\hline & Formal education & 140 & 51.4 \\
\hline \multirow[t]{4}{*}{ Religion } & Orthodox & 76 & 27.9 \\
\hline & Muslim & 134 & 49.3 \\
\hline & Protestant & 50 & 18.4 \\
\hline & Catholic & 12 & 4.4 \\
\hline \multirow[t]{4}{*}{ Marital status } & Married & 165 & 60.7 \\
\hline & Single & 58 & 21.3 \\
\hline & Divorced & 36 & 13.2 \\
\hline & Widowed & 13 & 4.8 \\
\hline \multirow[t]{2}{*}{ Residence } & Urban & 189 & 69.5 \\
\hline & Rural & 83 & 30.5 \\
\hline \multirow{2}{*}{$\begin{array}{l}\text { Number of people } \\
\text { living with }\end{array}$} & $<5$ & 210 & 77.2 \\
\hline & $>=5$ & 62 & 22.8 \\
\hline \multirow[t]{2}{*}{ Water } & Yes & 207 & 76.1 \\
\hline & No & 65 & 23.9 \\
\hline \multirow[t]{2}{*}{ Electricity } & Yes & 207 & 76.1 \\
\hline & No & 65 & 23.9 \\
\hline \multirow[t]{4}{*}{ Room } & 1 & 121 & 44.5 \\
\hline & 2 & 110 & 40.4 \\
\hline & 3 & 31 & 11.4 \\
\hline & 4 & 10 & 3.7 \\
\hline
\end{tabular}

*as Non-governmental organizations

were HIV positive and more than $70 \%$ of study participants had risky behaviours. For example, four out of five patients $(82.7 \%)$ reported not using condoms to protect themselves from sexually transmissible diseases.

\section{Mortality status of study participants}

Figures 1,2 and 3 respectively present mortality status of study participants by sex, WHO stage and TB type 
Table 2 Clinical and behavioural characteristics of Tb/HIV co-infected patients at JUTH, Southwest Ethiopia, 2013

\begin{tabular}{|c|c|c|c|}
\hline Variable $(n=272)$ & Value & Number & Percent \\
\hline \multirow[t]{2}{*}{ Disclosure } & Yes & 176 & 64.7 \\
\hline & No & 96 & 35.3 \\
\hline \multirow[t]{3}{*}{ Function } & Work & 138 & 50.8 \\
\hline & Ambulatory & 95 & 34.9 \\
\hline & Bed redden & 39 & 14.3 \\
\hline \multirow[t]{4}{*}{ WHO stage } & 1 & 17 & 6.3 \\
\hline & 2 & 67 & 24.6 \\
\hline & 3 & 124 & 45.6 \\
\hline & 4 & 64 & 23.5 \\
\hline \multirow[t]{2}{*}{ Regimen } & First line & 229 & 84.2 \\
\hline & Second line & 43 & 15.8 \\
\hline \multirow[t]{3}{*}{ CD4 } & $<200$ cells/copies & 163 & 59.9 \\
\hline & $>=200$ cells $/$ copies & 109 & 40.1 \\
\hline & Median (range) & $172.5(425)$ & - \\
\hline \multirow[t]{3}{*}{ TB type } & Pulmonary & 213 & 78.3 \\
\hline & Extra pulmonary & 14 & 5.2 \\
\hline & Mixed & 45 & 16.5 \\
\hline \multirow[t]{3}{*}{ Mode of TB entry } & New & 232 & 85.3 \\
\hline & Relapse & 27 & 9.9 \\
\hline & Dropout & 13 & 4.8 \\
\hline \multirow[t]{3}{*}{ Partner HIV status } & Positive & 189 & 69.5 \\
\hline & Negative & 1 & 0.4 \\
\hline & Unknown & 82 & 30.1 \\
\hline \multirow[t]{2}{*}{ Risky behaviour } & Yes & 191 & 70.2 \\
\hline & No & 81 & 29.8 \\
\hline \multirow[t]{2}{*}{ Condom use } & Yes & 47 & 17.3 \\
\hline & No & 225 & 82.7 \\
\hline \multirow[t]{2}{*}{ Tobacco smoking } & Yes & 126 & 46.3 \\
\hline & No & 146 & 53.7 \\
\hline \multirow[t]{2}{*}{ Alcohol drinking } & Yes & 76 & 27.9 \\
\hline & No & 196 & 72.1 \\
\hline
\end{tabular}

using Kaplan-Meier graphs. A total of 55 (20.2 \%) TB/ HIV co-infected patients died during the study period. In addition, records of three, four and seven participants showed lost to follow up, defaulting, and transferred out respectively. The 272 study participants contributed to 3 082.7 person month observations (PMO) to the current study.

\section{Predictors of mortality in TB/HIV Co-infected patients during TB treatment}

Table 3 presents predictors of mortality in TB/HIV Co-infected patients during TB/HIV treatment. Bivariate cox regression analysis showed that the risk of death was statistically different by age, educational status, occupation and WHO staging of HIV. After adjustment and checking the fitness of the model; being aged between 35-44 years, being a female sex worker (FSW), being a bed ridden functional status, and being WHO stages 2, 3 and 4 were independent predictors in the multiple Cox regression analysis.

\section{Discussion}

The current study indicates the occurrence of a significant mortality rate $(20.2 \%)$ amongst TB/HIV coinfected patients in JUTH. However, this finding was not dissimilar to the WHO reports that have shown TB's contribution of up to $26 \%$ of HIV mortality elsewhere [23]. Similar findings have also been echoed by studies in Ethiopia and Malaysia [16, 24].

Study participants whose ages were between 35-44 years old had nearly 3 times higher risk of $(\mathrm{AHR}=2.9$, $95 \%$ CI: 1.08-7.6) death than those below 25 years old, the finding which is similar with a study conducted in Brazil [10]. Some attribution to this occurrence could be that older patients are more likely to be diagnosed with HIV and/or TB late. It is well acknowledged that late diagnosis facilitates poor prognosis and deaths due to immune deficiency from rapid progression to Acquired Immune Deficiency Syndrome (AIDS) and extra-pulmonary tuberculosis [25-28]. This has implications for practice indicating the heightened need for early diagnosis and treatment of both HIV and TB. Similar to studies elsewhere [29], the odds of TB/HIV death was 9 times for CSW compared to other occupation such as government employees (AHR =9.1, $95 \%$ CI: 2.7-30.7). This finding is significantly important for nations health systems, and may have policy and practice implications in Ethiopia and elsewhere, including prioritizing this group as a key population and addressing their needs and designing more effectively targeted management.

Regarding functional status, bedridden patients had three times $(\mathrm{AHR}=3.2,95 \% \mathrm{CI}: 1.2-8.7)$ increased risk of mortality than patients recorded being in working status. This finding was in agreement with another study conducted in Bahir Dar, Ethiopia [16], where bedridden patients were reported to be nearly 4 times at risk of dying than patients in work functional status category $(\mathrm{AHR}=3.88 ; 95 \% \mathrm{CI}: 2.15-7.02)$. These findings do not come as a surprise because patients who are bedridden have probably been exposed to more infections and have poorer health outcome with vicious cycle of poorer immunity, which can lead to patients easily succumbing to opportunistic infections and death [30]. It is thus plausible to recommend mandatory and frequent screening for opportunistic infections and other diseases in 


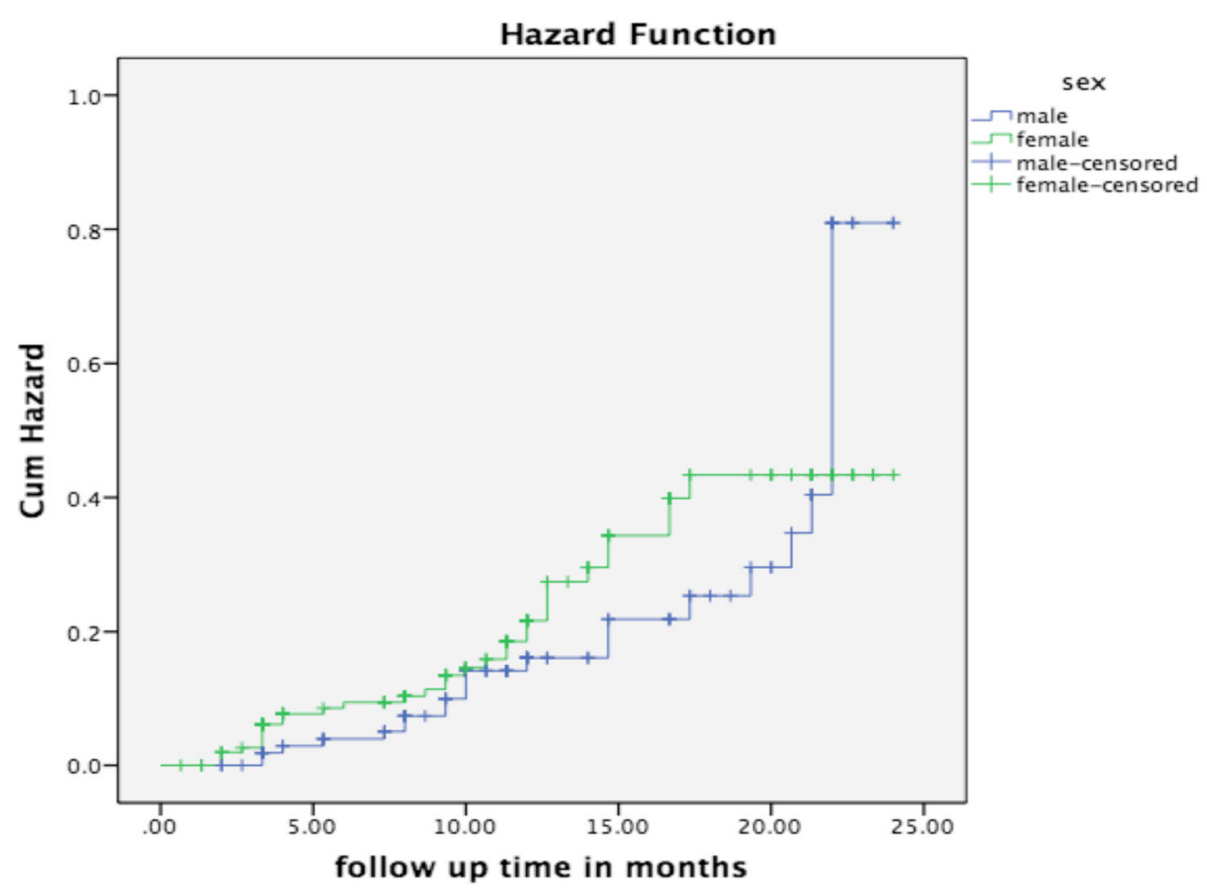

Fig. 1 Mortality status by sex-This figure presents mortality status of the study participants by sex using Kaplan-Meier. It shows that females died more than males

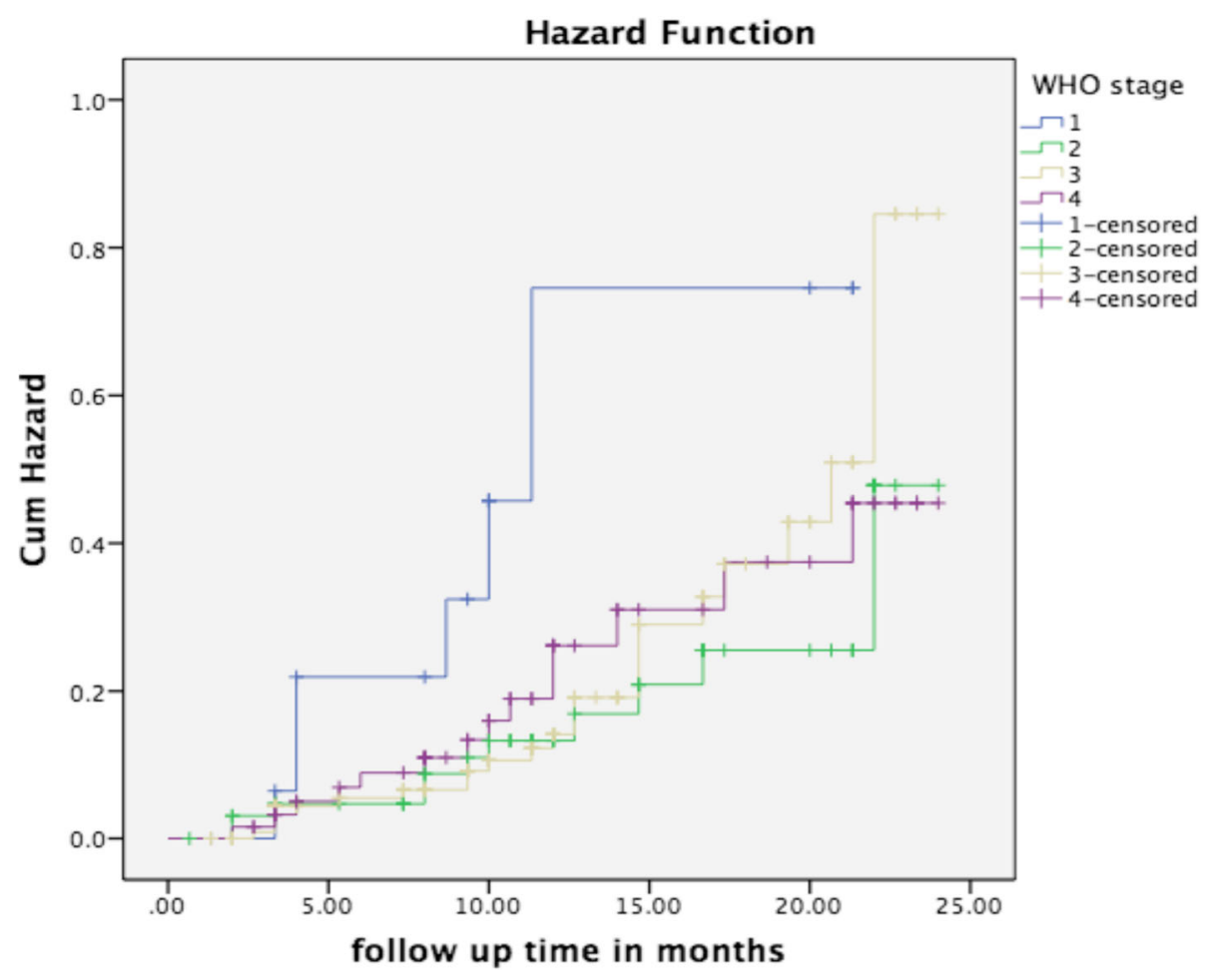

Fig. 2 Mortality status by WHO stage- This figure presents mortality status of the study participants by WHO stage using Kaplan-Meier. It shows that TB/HIV co-infected patients diagnosed as WHO clinical stage 1 died more than WHO clinical stages 2, 3 and 4 


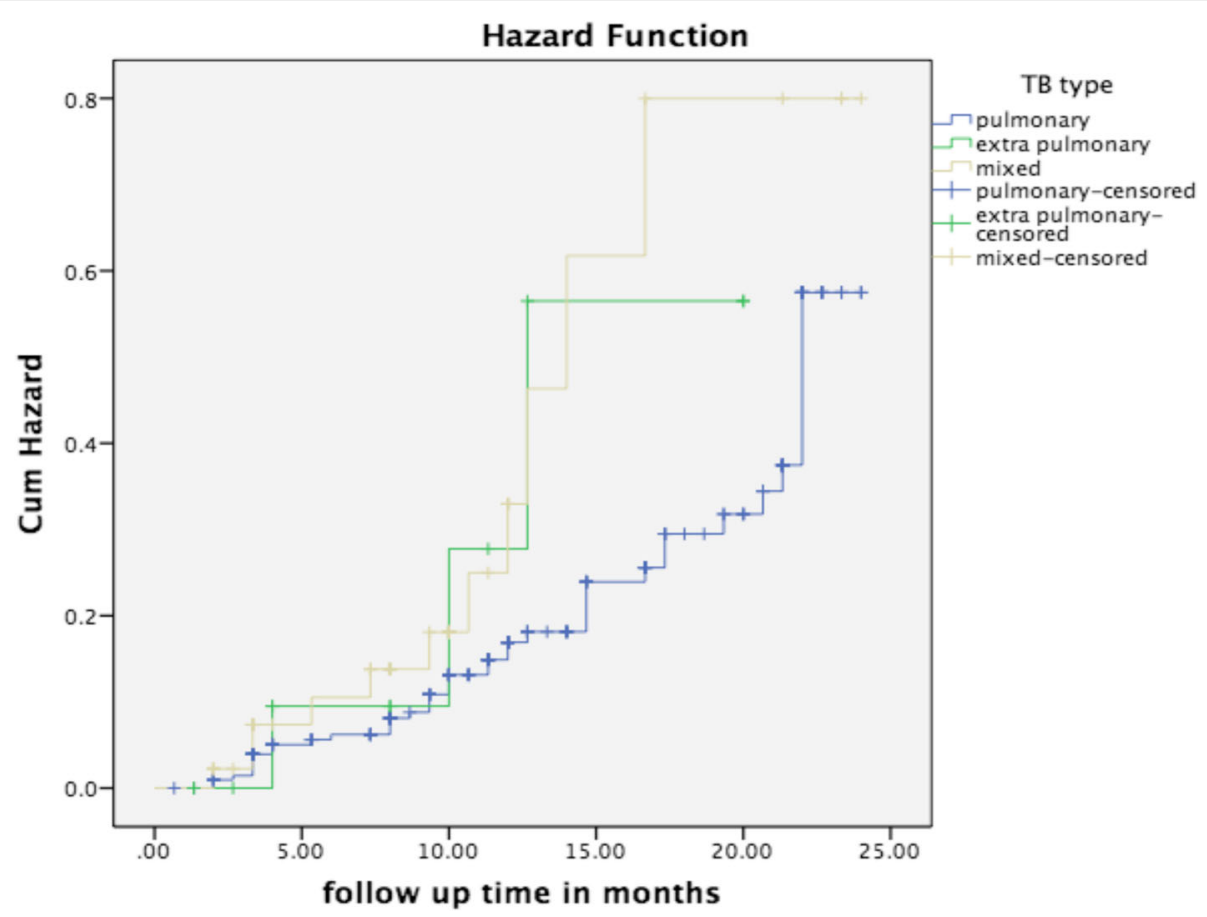

Fig. 3 Mortality status by Tuberculosis type- This figure presents mortality status of the study participants by tuberculosis type using Kaplan-Meier. It shows that TB/HIV co-infected patients diagnosed as pulmonary tuberculosis died less than extra-pulmonary tuberculosis

order to institute early and effective management strategies to reduce preventable mortalities.

Similar to the study conducted in Bahir Dar [16], the Kaplan-Meier graph on mortality status of TB/HIV coinfection by TB type, indicated that extra pulmonary TB patients in the current study died more than pulmonary TB patients. However, the findings of the current study were not statistically significant in the final model of the cox regression and we hypothesise that a small sample size could attribute to this effect.

Patients in WHO stages 2, 3 and 4 compared to stage 1 were found to have lower mortality risk. For example, the risk of dying in patients diagnosed as WHO HIV stage 3 was decreased by $70 \%(\mathrm{AHR}=0.3 ; 95 \% \mathrm{CI}$ : $0.1-0.8$ ) compared to WHO stage 1 patients. This is surprisingly uncommon, and contrasts findings from similar studies $[16,30,31]$. We hypothesise that these differences could be a result of paradoxical and unmasking types of TB-associated immune reconstitution inflammatory syndrome (TB-IRIS) [32]. IRIS is a clinical debilitating condition which occurs after the commencement of ARTs due to inflammatory responses against pathogens and presents with high fevers, distress, lymphadenopathy, meningitis, central nervous system lesions, ascites and radiological worsening of pulmonary infiltrates [33-35]. We thus argue that, when the patient passes the IRIS stage, it is likely to live longer than a patient at stage 1 who does not survive IRIS. However, this issue is a new and unique finding and warrants further research and exploration.

The major limitations of the current study were data incompleteness and small sample size. In addition, variables that could potentially have confounding effects such as alcohol abuse, income, illicit drug use, drug resistance, co-morbidities, treatment adherence and severity of immune suppression were not measured. Due to limitations in finance and human resources, the outcome status of defaulted, lost to follow-up and transferred out patients was not traced. This could have underestimated the incidence of death and subsequently affect the mortality estimates.

\section{Conclusions}

The findings of the current study have informed new unexpected predictor of mortality: higher mortality rate in WHO HIV stage 1 compared to WHO HIV disease stages 2, 3 and 4. It has also reaffirmed known significant predictors of the mortality for TB/HIV co-infected patients including being 35-44 years, being a CSW and being at bed ridden functional status. The occurrence of high death rates among TB/HIV co-infected cases needs actions to reduce this poor outcome. The findings of the current study have policy and practice implications and 
Table 3 Multiple cox regression predictors of mortality among Tb/HIV patients at JUTH, Southwest Ethiopia, 2013

\begin{tabular}{|c|c|c|c|c|}
\hline \multirow[t]{2}{*}{ Variable } & \multicolumn{2}{|c|}{ Tb/HIV Co-infection Status $(n=272)$} & \multirow[t]{2}{*}{ Crude Hazard Ratio (95\%Cl) } & \multirow[t]{2}{*}{ Adjusted Hazard Ratio (95 \% Cl) } \\
\hline & Alive, $n(\%)$ & Died, $n(\%)$ & & \\
\hline \multicolumn{5}{|l|}{ Age in years } \\
\hline $15-24$ & $32(14.7) 114$ & $6(10.9)$ & 1 & 1 \\
\hline $25-34$ & (52.5) 48 & $26(47.3) 21$ & $1.1(0.5-2.8)$ & $1.4(0.6-3.8)$ \\
\hline $35-44$ & $(22.1)$ & $(38.2)$ & $2.2(0.9-5.4)^{*}$ & $2.9(1.08-7.6)^{*}$ \\
\hline$>=45$ & $23(10.7)$ & $2(3.6)$ & $0.6(0.1-2.7)$ & $0.3(0.05-1.6)$ \\
\hline \multicolumn{5}{|l|}{ Sex } \\
\hline Male & $91(41.9)$ & $23(41.8)$ & 1 & 1 \\
\hline Female & $126(58.1)$ & $32(58.2)$ & $1.1(0.7-1.9)$ & $1.7(0.8-3.5)$ \\
\hline \multicolumn{5}{|l|}{ Educational status } \\
\hline Illiterate & $61(28.1)$ & $20(36.4)$ & 1 & 1 \\
\hline Read and write & $39(18)$ & $12(21.8)$ & $0.7(0.3-1.3)$ & $0.9(0.3-2.4)$ \\
\hline Formal education & $117(53.9)$ & $23(41.8)$ & $0.4(0.2-0.7)^{*}$ & $0.6(0.2-1.8)$ \\
\hline \multicolumn{5}{|l|}{ Occupation } \\
\hline Gov't employed & $40(18.4)$ & $8(14.5)$ & 1 & 1 \\
\hline NGO & $37(17.1)$ & $9(16.4)$ & $1.1(0.4-2.9)$ & $0.9(0.4-2.6)$ \\
\hline Farmer & 69 (31.8) & $11(20)$ & $1.06(0.4-2.6)$ & $0.7(0.3-1.9)$ \\
\hline Daily labour & $64(29.5)$ & $22(40)$ & $2.4(1.04-5.3)^{*}$ & $2.1(0.9-4.9)$ \\
\hline CSW & $7(3.2)$ & $5(9.1)$ & $6.7(2.2-20.9)^{*}$ & $9.1(2.7-30.7)^{*}$ \\
\hline \multicolumn{5}{|l|}{ Disclosure } \\
\hline Yes & $139(64.1)$ & $37(67.3)$ & 1 & 1 \\
\hline No & 78 (35.9) & $18(32.7)$ & $0.7(0.4-1.1)$ & $0.7(0.3-1.8)$ \\
\hline \multicolumn{5}{|l|}{ Function } \\
\hline Work & $112(51.6)$ & $26(47.3)$ & 1 & 1 \\
\hline Ambulatory & 79 (36.4) & $16(29.1)$ & $0.6(0.3-1.09)$ & $1.05(0.5-2.1)$ \\
\hline Bed ridden & $26(12)$ & $13(23.6)$ & $0.5(0.2-1.05)$ & $3.2(1.2-8.7)^{*}$ \\
\hline \multicolumn{5}{|l|}{ WHO stage } \\
\hline 1 & $11(5.1)$ & $7(12.7)$ & 1 & 1 \\
\hline 2 & $55(25.3)$ & $12(21.8)$ & $0.3(0.1-0.9)^{*}$ & $0.2(0.06-0.5)^{*}$ \\
\hline 3 & $101(46.5)$ & $23(41.8)$ & $0.4(0.2-1.02)$ & $0.3(0.1-0.8)^{*}$ \\
\hline 4 & $50(23.1)$ & $13(23.7)$ & $0.4(0.2-1.09)$ & $0.2(0.04-0.5)^{*}$ \\
\hline \multicolumn{5}{|l|}{ Tb type } \\
\hline Pulmonary & $172(79.3)$ & 41 (74.5) & 1 & 1 \\
\hline Extra-pulmonary & $11(5.1)$ & $3(5.5)$ & $0.6(0.3-1.07)$ & $2.6(0.5-12.2)$ \\
\hline Mixed & $34(15.6)$ & $11(20)$ & $1(0.3-3.6)$ & $0.9(0.3-2.7)$ \\
\hline \multicolumn{5}{|l|}{ Risky behaviour } \\
\hline Yes & $153(70.5)$ & $38(69.1)$ & 1 & 1 \\
\hline No & 64 (29.5) & 17 (30.9) & $0.9(0.5-1.6)$ & $0.8(0.4-1.9)$ \\
\hline \multicolumn{5}{|l|}{ Partner HIV status } \\
\hline Positive & $150(69.1)$ & 39 (70.9) & 1 & 1 \\
\hline Negative/Unknown & 67 (30.9) & $16(29.1)$ & $1.4(0.8-2.5)$ & $0.5(0.2-1.5)$ \\
\hline
\end{tabular}


they call for effective management strategies for TB/HIV co-infection including improved availability of early diagnosis and improved availability of ARVs to reduce this high death rates. Further studies are recommended with larger sample size in order to obtain comprehensive predictors of TB/HIV co-infection deaths.

\section{Additional files}

Additional file 1: Multilingual abstract in the five official working languages of the United Nation. (PDF $782 \mathrm{~kb}$ )

Additional file 2: Clinical and non-clinical data of Tb/HIV co-infectd patients attending in JUTH, Southwest Ethiopia. (SAV $17 \mathrm{~kb}$ )

\section{Abbreviations}

AHR: Adjusted Hazard Ratio; AIDS: Acquired immuno deficiency syndrome; ART: Antiretroviral therapy; FSW: Female sex worker; HIV: Human immunodeficiency virus; IRIS: Immune reconstitution inflammatory syndrome; JUTH: Jimma University Teaching Hospital; MDR: Multi drug resistance; PMO: Person month observation; TB: Tuberculosis; WHO: World Health Organization

\section{Acknowledgement}

We are grateful to JUTH and data collectors. Jimma University granted the study.

\section{Funding}

This research was funded by Jimma University and was received by Hailay Gesesw. The funders had no role in study design, data collection and analysis, decision to publish, or preparation of the manuscript.

\section{Availability of data and materials}

The dataset supporting the conclusions of this article is included within the article and its Additional file 2.

\section{Authors' contributions}

All authors contributed in designing of the study, data collection, data analysis, drafting and critically reviewing the manuscript. All authors read and approved the final manuscript.

\section{Authors' information}

$\mathrm{HG}$ is lecturer of Epidemiology in college of public health and medical science of Jimma University and a PhD student in the Discipline of Public Health in Faculty of Medicine, Nursing and Health Sciences, Flinders University. BT is lecturer of Biostatistics in the college of public health and medical science of Jimma University and a master's student in School of Statistics and Mathematics, Faculty of Science, Alberta University. DM is lecturer of Epidemiology in college of public health and medical science of Jimma University, and AG is lecturer of reproductive health in Department of population and Family Health, Jimma University. HK is a pharmacist in ART clinic of Filtu hospital in Somali, Ethiopia. LM is a senior lecturer and course coordinator of Master of Health and International Development in the Discipline of Public Health in Faculty of Medicine, Nursing and Health Sciences, Flinders University. All authors are currently staff members in their respective departments.

\section{Competing interests}

The authors declare that they have no competing interests.

\section{Consent for publication}

Not applicable.

\section{Ethics approval and consent}

Ethical clearance was obtained from the office of institutional ethical review board (IRB) of College of Health sciences, Jimma University. Waiver of the consent was obtained from IRB of JUTH and the reference number was RPGC/558/2012. The data access permission was obtained from JUTH board. No participant was involved in the study-we extracted anonymised data from the record.

\section{Author details}

${ }^{1}$ Department of Epidemiology, College of Health Sciences, Jimma University, Jimma, Ethiopia. ${ }^{2}$ Discipline of Public Health, Faculty of Medicine, Nursing and Health Sciences, Flinders University, Adelaide, Australia. ${ }^{3}$ School of Statistics and Mathematics, Faculty of Science, University of Alberta, Edmonton, Canada. ${ }^{4}$ Department of population and Family Health, College of Health Sciences, Jimma University, Jimma, Ethiopia. ${ }^{5}$ ART Clinic, Filtu Hospital, Somali, Ethiopia.

Received: 2 February 2016 Accepted: 19 October 2016

Published online: 05 December 2016

\section{References}

1. Toossi Z. Virological and immunological impact of tuberculosis on human immunodeficiency virus type 1 disease. J Infect Dis. 2003;188(8):1146-55.

2. WHO. WHO Global Tuberculosis report. 2012.

3. WHO. TB/HIV facts: 2012-2013. http://www.who.int/hiv/topics/tb/tbhiv_ facts_2013/en/ (Accessed on 13 June 2015)

4. WHO. Global tuberculosis 2015: 20th edition. http://www.who.int/tb/ publications/global_report/gtbr2015_executive_summary.pdf (Accessed 6 Apr 2016).

5. WHO. Tuberculosis fact sheets: Revised march 2016. http://www.who.int/ hiv/topics/tb/tbhiv facts 2013/en/ (Accessed on 6 Apr 2016)

6. Grant AD, Djomand G, De Cock KM. Natural history and spectrum of disease in adults with HIV/AIDS in Africa. AIDS (London, England). 1997;11(Suppl B): S43-54.

7. Ansari NA, Kombe AH, Kenyon TA, Hone NM, Tappero JW, Nyirenda ST, et al. Pathology and causes of death in a group of 128 predominantly HIV-positive patients in Botswana, 1997-1998. Int J Tuberc Lung Dis. 2002:6(1):55-63.

8. Datiko DG, Yassin MA, Chekol LT, Kabeto LE, Lindtjorn B. The rate of TB-HIV co-infection depends on the prevalence of HIV infection in a community. BMC Public Health. 2008:8:266.

9. Fekadu S, Teshome W, Alemu G. Prevalence and determinants of Tuberculosis among HIV infected patients in south Ethiopia. J Infect Dev Ctries. 2015:9(8):898-904

10. Domingos MP, Caiaffa WT, Colosimo EA. Mortality, TB/HIV co-infection, and treatment dropout: predictors of tuberculosis prognosis in Recife, Pernambuco State, Brazil. Cad Saude Publica. 2008;24(4):887-96.

11. Catala L, Orcau A. Garcia de Olalla P, Millet JP, Rodriguez-Mondragon A, Cayla JA. Survival of a large cohort of HIV-infected tuberculosis patients in the era of highly active antiretroviral treatment. Int J Tuberc Lung Dis. 2011;15(2):263-9.

12. Biadgilign S, Reda A, Digaffe T. Predictors of mortality among HIV infected patients taking antiretroviral treatment in Ethiopia: a retrospective cohort study. AIDS Res Ther. 2012;9(1):15

13. Tesfaye S, Abulie T, Tesfaye G, Dabere N, Demewoz H. Predictors of Mortality among Adult Antiretroviral Therapy Users in Southeastern Ethiopia: Retrospective Cohort Study. AIDS Research and Treatment 2015;2015.

14. Tadesse K, Haile F, Hiruy N. Predictors of Mortality among Patients Enrolled on Antiretroviral Therapy in Aksum Hospital, Northern Ethiopia: A Retrospective Cohort Study. PLoS ONE. 2014:9(1):e87392.

15. Alemu AW, Sebastian MS. Determinants of survival in adult HIV patients on antiretroviral therapy in Oromiyaa. Ethiopia Global Health Action. 2010;3 5398.

16. Sileshi B, Deyessa N, Girma B, Melese M, Suarez P. Predictors of mortality among TB-HIV Co-infected patients being treated for tuberculosis in Northwest Ethiopia: a retrospective cohort study. BMC Infect Dis. 2013:13:297.

17. Shaweno D, Worku A. Tuberculosis treatment survival of HIV positive TB patients on directly observed treatment short-course in Southern Ethiopia: A retrospective cohort study. BMC Res Notes. 2012;5:682.

18. Manda SO, Masenyetse $\mathrm{L}$, Lancaster JL, van der Walt ML. Risk of Death among HIV Co-Infected Multidrug Resistant Tuberculosis Patients, Compared To Mortality in the General Population of South Africa. J AIDS Clin Res. 2013;2 Suppl 3:7. 
19. Max R. O'Donnell, Nesri Padayatchi, Charlotte Kvasnovsky, Lise Werner, Iqbal Master, and C. Robert Horsburgh, Jr. Treatment Outcomes for Extensively Drug-Resistant Tuberculosis and HIV Co-infection. Emerg Infect Dis. 2013:19(3):416-24.

20. (CSA, ICF. Ethiopian Demographic Health Survey. Addis Ababa and Calverton: Central Statistical Agency (Ethiopia) and ICF International. 2012.

21. CSA. Population and Housing Census Report: Ethiopia. Central Statistical Agency. 2007.

22. WHO. Antiretroviral therapy for HIV infection in adults and adolescents. Geneva: WHO; 2010.

23. WHO. Global tuberculosis control: epidemiology, strategy, financing WHO report 2009. 2009.

24. Ismail I, Bulgiba A. Determinants of unsuccessful tuberculosis treatment outcomes in Malaysian HIV-infected patients. Prev Med. 2013:57(Suppl):S27-30.

25. Mojumdar K, Vajpayee M, Chauhan NK, Mendiratta S. Late presenters to HIV care and treatment, identification of associated risk factors in HIV-1 infected Indian population. BMC Public Health. 2010;10:416.

26. Xu X, Liu JH, Cao SY, Zhao Y, Dong XX, Liang Y, et al. Delays in care seeking, diagnosis and treatment among pulmonary tuberculosis patients in Shenzhen. China Int J Tuberc Lung Dis. 2013;17(5):615-20.

27. Raizada N, Chauhan LS, Babu BS, Thakur R, Khera A, Wares DF, et al. Linking HIV-infected TB patients to cotrimoxazole prophylaxis and antiretroviral treatment in India. PLoS One. 2009;4(6):e5999.

28. Tarekegn $\mathrm{S}$. The effect of HAART on incidence of tuberculosis among HIV infected patients in Hawassa University Referral Hospital: MSc Thesis. South Ethiopia Addis Ababa: Addis Abab University; 2011.

29. Garfein RS, Laniado-Laborin R, Rodwell TC, Lozada R, Deiss R, Burgos JL, et al. Latent tuberculosis among persons at risk for infection with HIV, Tijuana, Mexico. Emerg Infect Dis. 2010;16(5):757-63.

30. Addis Alene K, Nega A, Wasie Taye B. Incidence and predictors of tuberculosis among adult people living with human immunodeficiency virus at the University of Gondar Referral Hospital, Northwest Ethiopia. BMC Infect Dis. 2013;13:292.

31. Hailu R, Eshetu W. Survival of HIV-TB co-infected adult patients under ART in Ambo Referral Hospital, Ethiopia. Ethiop J Health Dev. 2013;27(2):88-93.

32. Kwan CK, Ernst JD. HIV and tuberculosis: a deadly human syndemic. Clin Microbiol Rev. 2011;24(2):351-76.

33. Harries AD, Zachariah R, Lawn SD. Providing HIV care for co-infected tuberculosis patients: a perspective from sub-Saharan Africa. Int J Tuberc Lung Dis. 2009;13(1):6-16.

34. Kaplan JE, Benson C, Holmes KK, Brooks JT, Pau A, Masur H. Guidelines for prevention and treatment of opportunistic infections in HIV-infected adults and adolescents: recommendations from CDC, the National Institutes of Health, and the HIV Medicine Association of the Infectious Diseases Society of America. MMWR Recomm Rep. 2009:58(Rr-4):1-207. quiz CE1-4.

35. Meintjes G, Rabie H, Wilkinson RJ, Cotton MF. Tuberculosis-associated immune reconstitution inflammatory syndrome and unmasking of tuberculosis by antiretroviral therapy. Clin Chest Med. 2009;30(4):797-810.

\section{Submit your next manuscript to BioMed Central and we will help you at every step:}

- We accept pre-submission inquiries

- Our selector tool helps you to find the most relevant journal

- We provide round the clock customer support

- Convenient online submission

- Thorough peer review

- Inclusion in PubMed and all major indexing services

- Maximum visibility for your research

Submit your manuscript at www.biomedcentral.com/submit
Biomed Central 